\title{
Que desencantamento do mundo? Comunicação, organizações e processos de racionalização no meio rural
}

\section{Carlise Schneider Rudnicki}

Doutora; Universidade Federal do Rio Grande do Sul carllise@hotmail.com

\begin{abstract}
Resumo
Propomos, neste artigo, descrever o desencantamento dos produtores de tabaco do Vale do Rio Pardo. Para tanto analisamos as relações entre organizações e sujeitos sob a perspectiva do pensamento weberiano, fundamentado, principalmente, nos conceitos de racionalização e de dominação. Entendemos que o ato de "obedecer", que confronta diferentes racionalidades, acontece não essencialmente devido à ordem que as pessoas creem ser legítimas, mas que acreditam ser inevitáveis. As análises foram realizadas conforme a sociologia compreensiva de Max Weber, de forma qualitativa, utilizando como técnica grupos de discussão e entrevistas em profundidade com famílias rurais que plantam tabaco e vivem no Vale do Rio Pardo/RS, Brasil. Observamos nas organizações deste rural a comunicação em uma perspectiva instrumental e conectada à ideia de desenvolvimento econômico. Verificamos que, desencantados, os sujeitos instituem um comportamento de recusa às mudanças institucionais.
\end{abstract}

\section{Palavras-chave}

Comunicação. Racionalização. Dominação. Organizações. Rural.

As pancadas de teu martelo que teu credor escuta às cinco da manhã ou às oito da noite o deixam seis meses sossegado; mas se te vê à mesa de bilhar ou escuta tua voz numa taberna quando devias estar a trabalhar, no dia seguinte vai reclamar-te o desembolso, e exigir teu dinheiro antes que o tenhas à disposição, duma só vez (WEBER, 2004, p. 43-44). 


\section{Introdução}

Propomos, neste artigo $^{1}$, descrever o desencantamento dos produtores rurais do Vale do Rio Pardo. Para tanto analisamos as relações entre organizações e sujeitos sob a perspectiva do pensamento weberiano, fundamentado, principalmente, nos conceitos de racionalização e de dominação. Observamos que, nas organizações encontradas nas regiões da pesquisa, a comunicação permanece em uma perspectiva instrumental e conectada à ideia de desenvolvimento econômico.

No Brasil, o maior exportador mundial de tabaco e o segundo maior produtor mundial (AFUBRA, 2015), o cultivo de tabaco concentra-se, principalmente, nos três estados da região sul: Rio Grande do Sul, Santa Catarina e Paraná. Em 2005, o país assinou um tratado internacional de saúde pública, a "Convenção-Quadro do Controle do Tabaco (CQCT)". Após, iniciaram-se mudanças no cenário organizacional, político e econômico; elas significaram uma diminuição da área plantada do tabaco (AFUBRA, 2015). Paralelamente, campanhas antitabagistas acontecem no país, proporcionando uma queda de 30\%, de 2006 a 20014, do número de fumantes no país (VIGITEL, 2015). Verificamos, então, relações entre meio ambiente e saúde humana.

Buscando entender estas significações, consideramos que as organizações, em particular as empresas (públicas ou privadas), têm assumido papéis cada vez mais relevantes na construção da sociedade através das relações econômicas, políticas, sociais e culturais. Tendo vista os jogos complexos que se materializam nas comunidades em que se inserem, podem ser consideradas agentes de manutenção e de transformação da cultura (BALDISSERA, 2001). De alguma forma, elas orientam padrões e valores a serem assumidos pela população local, chegando, muitas vezes a disputar forças com o poder público.

Por isso, a partir de uma perspectiva da comunicação como produção e disputa de sentidos (BALDISSERA, 2004) e relações de dominação, percebemos como as diferentes racionalidades (que fornecem sentido às nossas ações) coabitam o cotidiano dos sujeitos. Conforme autores que estudam os modos de vida no meio rural, nas relações baseadas em amizade e parentesco (WANDERLEY, 2001) importa a reprodução econômica e social do grupo, caracterizando-se com a não separação entre vida e trabalho (WORTMANN; WORT-

\footnotetext{
${ }^{1}$ Projeto intitulado "Comunicação, relações de poder e sistema do tabaco: discursos e estratégias de visibilidade e legitimidade empregados por Ong's, organizações públicas e indústrias do tabaco na mídia do Vale do Rio Pardo - RS”, tem como objetivo geral compreender, sob a perspectiva da comunicação, como se estruturam as relações de poder na articulação entre as organizações voltadas à saúde pública (tais como Ong's, ANVISA, INCA) e as organizações do setor do tabaco, a partir de seus discursos na mídia do Vale do Rio Pardo - RS. 0 estudo, que iniciou em 2012 e será finalizado em 2016, tem como fontes financiadoras CAPES e FAPERGS, a partir do Edital DOCFIX/09, sob supervisão do Prof. Dr. Rudimar Baldissera, PPGCOM/UFRGS.
} 
MANN, 1997). Entretanto, crescem as perspectivas de um novo rural, heterogêneo (KAGEYAMA, 2008), multifuncional (SCHNEIDER, 2009), multinível e multiatores (PLOEG, 2009).

Considerando-se estas mudanças, e percebendo a importância das organizações para a sociedade, porquê estudá-las, questiona Souza (2012). Quando se fala sobre desenvolvimento, prossegue o autor, geralmente se pensa sobre o tipo de desenvolvimento desejado e o papel dos agentes e das políticas públicas frente aos sujeitos que as "recebem". Nesse sentido, as organizações no meio rural seriam uma lacuna, mais precisamente a dimensão organizacional de pensamento e das ações do desenvolvimento. Isso, lembra Souza, porque as políticas e intervenções são organizadas e implementadas por organizações das mais diversas - privadas, não governamentais e governamentais.

Para Weber, as instituições não determinam o comportamento dos indivíduos, mas os orientam. E em relação às normas propriamente ditas (exigência de novos comportamentos em relação ao meio ambiente e ao trabalho, por exemplo), destacamos que não explicam a ação dos sujeitos. De fato, a norma pode influenciar a conduta com diferentes graus de consciência, seja via costume (tradição, cultura), cálculo utilitário ou pelo respeito valorativo da norma (obediência). A apropriação que o ator social faz desta norma é o que explicita a importância da percepção das subjetividades.

O trabalho moderno, segundo Max Weber, é pensado como uma especialização que permite as aquisições, antes construídas como pecado. Não obstante, ele não apresenta condições para a realização de uma vocação, mas como meio para viver. Ou, conforme ThiryCherques, "Permite a sobrevivência, mas não dá o sentido da vida." (THIRY-CHERQUES, 2009 , p.910). 0 trabalhador pode ter a sua vinculação legitimada por qualquer dessas ordens e por outras, não descritas por Weber. 0 que importa é ele obedecer.

Assim, os tempos pré-modernos caracterizavam-se por estarem embalados por um manto sagrado, imersos em tradições e dogmas religiosos que modulavam de forma significativa as condutas. Com o desenvolvimento do cientificismo e a exacerbação da lógica capitalista, a magia foi substituída, conforme Parsons (2010), por uma "gaiola de ferro" que provocaria um "desencantamento do mundo". Para Weber (1998), o fenômeno da racionalização significa o desenvolvimento ocidental, a sujeição das subjetividades frente a comportamentos racionais. Nesta perspectiva, há uma concatenação de interesses, ou mesmo um "acidente", ou acaso, que não é vazio de significação (WHIMSTER, 2009). Conhecer estes "acidentes", como tudo acontece e quais interesses ideais estão implicados no surgimento destes é algo que deve ser compreendido. 
Perante à ideia de desenvolvimento, entendemos que cada força em disputa (organizações públicas, privadas e outras forças) procura promover, tornar públicos seus interesses e representações de mundo - suas "verdades" -, bem como obter opiniões favoráveis. Portanto, consideramos a comunicação como "processo de construção e disputa de sentidos" (BALDISSERA, 2004). Também é pela comunicação que determinadas concepções de mundo, assumidas como verdades pelos diferentes sujeitos podem ser questionadas e, mesmo, revistas.

Para Weber, a ideia de dominação está presente em todas as relações. 0 poder “[...] significa toda a probabilidade de impor a própria vontade numa relação social, mesmo contra resistências, seja qual for o fundamento dessa probabilidade." (WEBER, 1988, p.43); e a dominação "a probabilidade de encontrar obediência", ou ainda, é a própria materialização do poder.

Utilizando tal referencial, partimos para o campo. Em primeiro lugar foi realizada uma pesquisa bibliográfica e documental, a partir de dados secundários, reportagens na mídia local e publicações científicas. Em um segundo momento, preparamos entrevistas em profundidade e organizamos grupos de discussão com a população rural. 0 critério de escolha dos grupos de discussão foi: a) sujeitos produtores de tabaco do Vale do Rio Pardo/RS e b) indivíduos com certo grau de proximidade (parentesco ou amizade). As discussões aconteceram, conforme o método de William Gamson (2011). Foram realizadas nas casas dos sujeitos, sempre com pessoas que se conheciam.

Para definirmos a quantidade de grupos e indivíduos consideramos o critério da saturação; quando as respostas começaram a se repetir, sem acréscimo de novas informações, interrompemos a marcação de novos encontros.

\section{Sobre as organizações e os sujeitos da pesquisa}

A ideia de agricultura que, tempos atrás, estava relacionada ao atraso, distância e pobreza, passa por inúmeras transformações, em diferentes dimensões e temáticas (segurança e soberania alimentar, sustentabilidade e mudanças climáticas). Com a introdução das questões agroecológicas, sob a perspectiva da nova Política Nacional de Assistência Técnica e Extensão Rural (PNATER), novas expectativas sobre o campo são formuladas.

Tal política propõe às entidades e agentes de extensão rural estratégias de sustentabilidade socioeconômica e ambiental (CAPORAL e COSTABEBER, 2007). Entretanto, para aqueles que trabalham e vivem dos frutos da terra o fato de pensar novas alternativas, de 
viver o desenvolvimento de uma forma mais sustentável, tem causado estranhamento e resistência.

Dentre as organizações ressaltadas pelos sujeitos da pesquisa evidenciaram-se centros de pesquisa e de extensão rural, como a Empresa de Assistência Técnica e Extensão Rural/RS (Emater), órgãos de saúde pública (Instituto Nacional do Câncer, INCA), de vigilância sanitária (Agência Nacional de Vigilância Sanitária, ANVISA) e organizações nãogovernamentais (Aliança de Controle do Tabagismo, ACTBr). Sublinhamos, conforme KAGEYAMA (2008), que projetos propulsores de um desenvolvimento que engloba múltiplas dimensões (sociocultural, econômica, ambiental, institucional e política) deve ter o cuidado em pautar-se em um formato não assistencialista.

No que diz respeito ao sistema de governança das organizações privadas, as relações são consagradas a partir de contratos formais e informais, através dos instrutores agrícolas contratados que mantém relações de parentesco ou amizade com os agricultores. Os incentivos de colaboração das partes têm sido permeados por sistemas de incentivos baseados em sanções. As cláusulas contratuais legais que pretendem incentivar comportamentos "desejáveis", como a abolição do uso de mão de obra infantil-juvenil, manejo do solo, não uso da mata nativa, conforme verificamos na análise dos resultados, não têm encontrado uma adesão satisfatória, conforme relatos das empresas e dos agricultores.

As exigências perante os novos cenários são inúmeras. Os contratos exigem, por exemplo, a verificação do comparecimento dos filhos menores de 18 anos na escola, até 90 dias após o final de cada ano letivo. Para isso, a cadeia produtiva criou para esse público o "Instituto Crescer Legal".

No que tange à saúde do agricultor, ocorre uma dificuldade prática de uso dos equipamentos de proteção individual (EPI). Durante a colheita, mesmo com desmaios frequentes, o calor e o formato da roupa causam o pouco uso desta. Se os cuidados com a própria saúde não são prioridade, como privilegiar a integridade do outro?

Luiz Beltrão (2001) ressalta conflituosas relações estabelecidas entre a nossa elite, inclusive a intelectual, e os sujeitos situados à margem do processo capitalista, rurais e urbanos. Tal movimento desloca o poder de decisão, sem se preocupar sobre a forma como as pessoas reagem às sugestões feitas, às novas maneiras de trabalhar, de agir e de se organizar. 0 autor reflete sobre a forma como a comunicação foi desvinculada da cultura, da política; resta, de alguma forma, a informação do lugar da troca, da negociação. 
Beltrão ainda retrata a dicotomia ética e cultural entre as massas (da cidade e do campo) e as elites dirigentes, estes últimos assumindo posições e tomando decisões. Ainda "[...] não se procurou pesquisar a maneira pela qual o povo reage às sugestões que lhe são feitas [...]" e "[...] teimosa, obstinadamente, o povo conserva a sua inteligência e, através dela, passam os episódios que julgamos comuns e irresistíveis." (BELTRÃO, 2001, p. 62). A técnica transmitida, se não experimentada pelos atores, pouco encontra espaço no cotidiano destes.

Bordenave, na década de 80, definiu a comunicação no meio rural como “[...] o conjunto de fluxos de informação, de diálogo e de influência recíproca existentes entre os componentes do setor rural e entre eles e os demais setores da nação afetados pelo funcionamento da agricultura [...]." (BORDENAVE, 1985, p.7).

Apostilas de entidades como a Emater ilustram que muito precisa ser discutido, já que os processos comunicacionais têm sido reduzidos à apresentação de um apanhado de técnicas ou metodologias, sendo, ainda hoje, considerados "sinônimo de difusão de tecnologias" (FONSECA, 2003, p.96) frente ao desenvolvimento econômico das regiões.

Assim, como o viés econômico atravessa todo o sistema do tabaco (e toda a sociedade), parece evidente que as questões simbólicas (imaginários, representações, construções de mundo, cultura) são permanentemente acionadas para, discursivamente, reforçar determinadas concepções, mitos, tabus, "verdades" e ritos em detrimento de outras visões de mundo. Da mesma forma, também é pela comunicação que determinadas concepções de mundo, assumidas como verdades pelos diferentes sujeitos podem ser questionadas e, mesmo, revistas. Sistemas organizacionais pressupõem, necessariamente, processos comunicacionais. Daí a necessidade de estudos sobre os processos comunicacionais, como o que se está propondo aqui, para que possamos considerar essa variável, que é fundante dos processos organizativos e organizadores.

As organizações, em um formato instrumental e persuasivo, apontam novas e/ou mais adequadas técnicas ao cotidiano do produtor rural. No entanto, Woortmann e Woortmann (1997) destacam, fundamentados em Alexander Von Chayanov, que se tem discutido não um "saber" camponês, mas uma "rotina" camponesa, um "instinto" que se opõe à inovação. E o trabalho na terra produz um cultivo e uma cultura com saberes técnicos singulares. Ademais, de acordo com os autores, as ações comunicadas discursivamente pelos sujeitos ao pesquisador ganham múltiplos significados e tornaram inteligíveis somente quando explicadas pelos mesmos, pois é um saber que nós não praticamos. 
Com as mudanças promovidas nos lugares ordinários, a partir da ratificação da CQCT, estes significados se apresentam, proliferam, tendo em vista acordos, regras e legislações firmados através de articulações, disputas de poder e lobbies junto aos governos federal, estaduais e municipais, no âmbito das políticas públicas. Tais negociações envolvem as empresas, partidos políticos, movimentos sociais, governos, mídia e entidades representativas (do setor tabagista e dos agricultores).

Os cenários produzidos pela mídia também mediam o cotidiano dos agricultores em estudo. Manchetes de matérias veiculadas no jornal mais tradicional do Vale do Rio Pardo, "A Gazeta do Sul", demonstram, paralelamente, o medo da saída das empresas da região, a riqueza gerada pela cadeia produtiva, a tradição do plantio e a luta do setor contra as medidas de saúde (SCHNEIDER, 2011; MENDES, 2013; GEHRKE, 2014; TREICHEL, 2012, 2015).

As discussões sobre as incertezas a respeito do cenário mundial de produção e de exportação do tabaco, a partir de um discurso econômico, mesclam-se com a tradição do plantio. Segundo os entrevistados, o rádio, dentre todas as mídias, foi eleito o mais próximo do seu cotidiano. Apesar do rádio, que atinge maior número de pessoas, a comunicação das empresas foi destacada como a mais acessada pelos entrevistados. Além das novidades e informações sobre o setor produtivo, apresentadas pelo orientador técnico agrícola, as revistas institucionais divulgam em reportagens programas como "Produtor 10" e "Propriedade Sustentável”; criando produtores modelos, exemplares, "vitoriosos", ricos, tipos distantes da realidade das 200 mil famílias produtoras de tabaco no sul do país.

Ainda conforme os sujeitos, a mídia noticia, diariamente, a preocupação econômica (saída das empresas), a tradição do plantio e os "riscos" que as organizações voltadas à saúde pública têm ocasionado no Vale do Rio Pardo, já que se opõem ao desenvolvimento de territórios em que há cultivo de tabaco.

As empresas constroem e são construídas no ambiente sociocultural, tendo como meio fundante o processo comunicacional que, mediante estratégias formalmente materializadas, visam sua própria institucionalização. Assim, conhecer a comunicação de uma determinada organização implica desvelar as codificações que fluem nas relações que se estabelecem nesse sistema. A relevância do desvelo das codificações pode ser melhor entendida a partir da compreensão dos códigos como convenções sociais materializados em linguagens. As linguagens possibilitam que os sistemas sejam mantidos (reiteração dos códigos vigentes, explícitos e implícitos) ao mesmo tempo em que são o espaço de mudanças, de rupturas e de instauração de novos códigos. 
De um lado, a mídia no Vale do Rio Pardo ressalta o senso comum de que eles praticam uma atividade altamente rentável e lucrativa e, apesar de demandar uso intenso de mão-de-obra, pode ser realizada em pequenos lotes de terra. Por outro, ressaltam os altos custos com mão de obra, agrotóxicos e investimentos em infraestrutura. De todo modo, a produção de tabaco pelos agricultores. 0 Sistema Integrado de Produção do Tabaco (SIPT) viabiliza a inserção dos agricultores no mercado, garante a compra da safra e fornece as informações "necessárias" ao plantio; ora se traduz em "segurança" para os agricultores, ora "zona de conforto".

Ao receberem na propriedade os contratos, levados pelo orientador técnico das empresas, bem como os insumos e a assistência técnica, afirmam não haver necessidade de buscar mais informações em outros locais e fontes. Os técnicos agrícolas e gerentes de produção das organizações consideram os agricultores "acomodados", pessoas que não buscam informação e que não desejam mudanças, melhorias na sua propriedade e na sua qualidade de vida.

Os discursos dos executivos das empresas, e mesmo dos técnicos agrícolas, exprimem um desejo de mudar o comportamento do agricultor. Desse modo, as organizações estimulam os agricultores, a partir do SIPT, a ter atitudes empreendedoras. Conforme um agricultor,

Eles querem que a gente goste de achar bom não usar agrotóxico e trabalhar mais, que se goste de fazer coisa difíceis que são boas para eles da cidade. $E$ depois acham caro, na feirinha que uns vende (sic) coisas sem muito veneno, porque acham que a gente tem que vender barato (Agricultor $22,2014)$.

Os agricultores mantêm o discurso de que a renda é o fator principal de permanência no cultivo do tabaco; apesar de estarem, permanentemente, endividados, junto às empresas. Assim, relatam que estão sob dominação, pois não conseguem sair do sistema. Destacam também que os orientadores agrícolas são "fofoqueiros" e que as notícias sobre os cenários político e econômico são "mentirosas"; destacam que acessam a internet, mas não sabem onde procurar informações, já que a mídia local também não é "confiável" e os "grandes" jornais são "difíceis de comprar ou de encontrar as notícias".

Mesmo assim, os instrutores técnicos apresentam-se como os principais atores na manutenção do Sistema de Produção Integrada, tendo em vista as relações de proximidade consolidadas entre o instrutor e a família produtora de tabaco, as quais são significativas. Quando questionados sobre a relevância de ter um familiar ou um amigo como orientador 
técnico, os entrevistados dizem que sim. A duplicidade de sentidos (orientador confiável como representante da organização não confiável) propicia uma ideia de racionalidade pautada além das punições e sanções. Mas essa relação entre organizações e sujeitos também se orienta a partir de ordens estatais, neste caso, a partir do acordo assinado via CQCT.

Sendo a relação contratual entre empresas e agricultores mediada pelo instrutor técnico, o único momento em que há possibilidade de ligação direta do agricultor (nem todos têm condições financeiras de ir até a empresa e a produção é retirada pela empresa) é no momento da venda da folha em fumo.

Considerado o mais crítico pelo produtor, a "pior época da vida" e "ainda por cima eles nos roubam bem no Natal, no Réveillon". Ao presenciarmos a classificação do fumo em folha², durante a venda, presenciamos diversos agricultores revoltados: “É pegar ou largar, eles dizem". Apenas alguns, com condições financeiras para pagar o transporte do seu produto de volta à propriedade, não aceitam a classificação, o valor estipulado pela empresa.

\section{A relação entre os sujeitos e as organizações sob a perspectiva weberiana}

Na tradição weberiana os indivíduos se movimentam dentro de uma rede em que, quanto mais adaptado por sua consciência e vontade, "melhor" será ele e a sociedade. Isso implica inclusive em um cálculo, diferente da lógica marxista da alienação, no qual o sujeito avalia ganhos e perdas. Nos debates da tradição marxista, também presentes no estruturalismo dos anos 50 e 60, se apresentam construções, não de um tipo ideal, mas que se referem à ideia de relações de produção, de como os sujeitos se alienam nas relações de produção. Para a tradição marxista, a questão central é a liberdade e não necessariamente a possibilidade de encaixe numa sociedade. Ela possui sempre a ideia de alienação; mesmo o sujeito que se organiza na sociedade encontra-se alienado.

Sem a intenção de reconstruir a teoria em sua totalidade, tanto no que tange ao conteúdo, como na amplitude das interpretações sobre esta, pretendemos refletir sobre o destaque que os aspectos econômicos apresentam para os agricultores, a forma pela qual esses fenômenos influenciam o grupo e o modo pelo qual são influenciados por eles. Ou seja, a economia pode influenciar a religião, e vice-versa. Importa destacar que, para o autor, a racionalidade institucionalizada não significa progresso, mas uma tentativa de controle.

${ }^{2}$ A compra e a classificação do fumo são regulamentadas por Portaria de Classificação, emitida pelo Ministério da Agricultura. Existem 48 tipos de classificação do fumo e o valor pago é estabelecido conforme o tipo de fumo, a posição da folha na planta, a cor e a qualidade. 
Sendo a realidade fragmentada, principalmente em relação ao que se apresenta como novidade, as racionalizações são tentativas de dar sentido a uma "não racionalidade", contida nas desconexões que se apresentam no cotidiano. Ao tentar entender como se constroem as relações e os processos de racionalização nos movimentos das ações, Weber (1998) destaca diferentes possibilidades de ação social conforme os motivos que a geram.

A ação social relaciona-se ao sentido (significado ou intenção) que o agente oferece à sua ação. Ou, "Em outros termos, é o significado subjetivo, presente no agente, com suas partes indissociáveis: os motivos que o levaram a agir desse modo e não de outro e as consequências que a ação desencadeou no mundo" (LEAL, 2008, p.83).

A racionalidade vem sendo interpretada por diferentes autores (EISEN, 1978; LEVINE, 1981; SCHLUCHTER, 1979, dentre outros). Aqui propomos, conforme Levine (1981), pensála em duas dimensões: substantiva e objetiva. A primeira trata dos tipos de ação, para Sell, “[...] a racionalidade como qualidade mental da ação estaria presente na distinção weberiana entre compreensão racional e compreensão empática e na sua diferenciação entre formas racionais e não racionais de ação social." (SELL, 2012, p. 158); a objetiva, encontrada em diferentes espaços de vida e momentos, apresenta quatro formas de racionalidade, instrumental, quando estimuladas pelos resultados que serão atingidos e voltada aos fins a serem alcançados mediante um cálculo preciso dos meios; conceitual, o domínio da realidade pela via da abstração e da generalização; substantiva/material, com sentido mais vago, revela que as considerações não se satisfazem somente com o que é calculado racionalmente, buscando um fim e pensando em meios para atingi-lo, mas deve levar em conta "postulados valorativos" através de exigências éticas, políticas, hedonistas ou utilitaristas; e formal, uma forma de submeter particularismos a regras, hierarquias e especialização.

Como categoria central da racionalidade temos o "cálculo", que se institui a partir de lutas sociais e de escolhas. Há um conjunto balizado pela ideia de valores que guiam as decisões dos indivíduos. Entretanto, Weber concebe a racionalidade conforme os valores da constatação de que a vida é perpassada pelo irracionalismo do mundo, com o qual se deve constantemente lidar. E essa irracionalidade também pode ser pensada na perspectiva da "vocação", explicando alguns conflitos nas relações entre empresas e agricultores. Isso porque explicita que não é apenas o significado "trabalho", mas também o conhecimento técnico, a tradição, o saber fazer, o trabalho em família e a missão. Weber concebe a racionalidade perante a constatação de que a vida é perpassada pelo irracionalismo do mundo, com o qual se deve constantemente lidar. 
Na ética protestante (2004), o sujeito incorpora uma lógica que a tradição lhe traz, nesse caso o catolicismo, que é a ideia da culpa: eu não consigo chegar ao paraíso, eu não consigo fazer a terra nova, não consigo realizar a missão divina. Se a lógica moral é fundamentalista e o sujeito consegue pensar a partir de outra perspectiva, mais racionalmente econômica, como este sujeito irá conseguir se organizar sem necessariamente se reconciliar às questões de ordem moral? Sem ser "jogado na fogueira"?

No terceiro capítulo desta mesma obra, Weber busca compreender um sujeito que vive segundo valores pessoais diante de um mundo moderno. Para isso, é necessário descobrir até onde este sujeito irá impor seus valores para esse mundo. Portanto, a sociologia compreensiva não surgiu como uma necessidade para diferenciar os tipos de agricultores ou famílias rurais, mas sim como elemento em busca de um entendimento dos comportamentos que se percebe possuir importância para permitir entender as diferentes percepções de mundo que se expressam nas suas relações com o trabalho (vocação).

Assim, o método pretende, no rastreamento das intenções dos agentes, a construção de um quadro ideal-típico (perfeito e hipotético), que possibilite entender as intenções dos indivíduos, repletas de tendências irracionais, afetos, acasos; que possibilite captar o imprevisível e o indeterminado. 0 autor critica a previsibilidade nas ciências naturais e busca demonstrar o quanto a vida social é dependente da capacidade de prever a reação dos sujeitos diante de um estímulo; oferece a possibilidade de se ir além da observação do curso externo dos eventos. Tais contribuições indicam caminhos que revelam além da racionalidade aparente, dos cálculos lógicos, propiciando análises que levam em conta as irracionalidades do cotidiano.

As pessoas que se movimentam no sistema de produção integrada apresentam trajetórias dotadas de uma série de outros recursos (que não apenas cultura, educação e renda), como a identidade local e o reconhecimento do seu trabalho. As irracionalidades (emoções) passam a ser cogitadas conforme os diferentes tipos de ação e dominação; de forma similar; a luta não se encontra apenas calcada nas necessidades privadas, mas também nas coletivas.

Quando se fala em espaços de luta é importante ponderar que, em todos os espaços, inclusive de dominação e crenças, o que leva o pesquisador a buscar as motivações dos indivíduos são as características que estimulam ou bloqueiam suas relações com as organizações. Por esse motivo, entender tais características e os contextos em que se constroem, são primordiais para entender o processo de construção destas relações. 
No caso das empresas de tabaco, os contratos firmados entre agricultores e organizações servem como instrumentos de controle que, para Weber, não garantem que os agentes “obedeçam” às normas impostas, eis que estes dispõem de outras, não explícitas. Mesmo que relações complexas não sejam resolvidas, a tentativa de controle autorizaria pensar que o controle irá funcionar. Esta é a lógica das ações baseadas no controle e encontradas nos programas que a cadeia produtiva do tabaco organiza.

Em 2011, o setor produtivo do tabaco - entidades e as empresas do setor - assina um termo de compromisso junto ao Instituto Brasileiro do Meio Ambiente e dos Recursos Naturais Renováveis (Ibama) e ao Ministério do Meio Ambiente. $\mathrm{O}$ acordo conta com a distribuição de cartilhas aos produtores e a capacitação dos orientadores técnicos; Frente às normas ambientais vigente, a Souza Cruz Tabacos, empresa que lidera ações voltadas às mudanças institucionais, cria o "Programa Amigos da Mata Nativa" (SOUZA CRUZ, 2015), que pretende garantir a preservação da mata nativa nas propriedades rurais em que atua, em parceria com instituições regionais, como prefeituras e federações de trabalhadores. Embasadas na capacitação de orientadores agrícolas, os agentes buscam conscientizar os produtores sobre a utilização de lenha reflorestada.

\section{Sociologia compreensiva e comunicação no meio rural}

A metodologia compreensiva e a análise histórica ("a história que nunca passa") nos possibilita pensar de forma mais aprofundada sobre as motivações dos indivíduos e, portanto, sobre o controle destes comportamentos, também a partir das tradições, dos costumes. Ou seja, o tempo passado ainda faz parte do presente, motivando as ações dos agentes e podendo explicar porque determinados mecanismos de governança não funcionam. “[...] individualidade histórica, isto é, um complexo de conexões que acontecem na realidade histórica e que nós encadeamos conceitualmente em um todo, do ponto de vista de sua significação cultural" (WEBER, 2004, p. 41). São os sujeitos quem determinam os sentidos, haja vista que alguns fenômenos são mais importantes do que outros.

0 ato de compreender os sentidos, a partir do processo de racionalização do mundo, para Weber, pode ser encontrado nas diferentes formas de dominação encontradas nas relações sociais. 0 sujeito presta obediência a uma ordem conforme motivos de submissão à autoridade, a partir dos tipos de dominação, como a tradicional; a carismática e a racionallegal, ou burocrática. A primeira se caracteriza pela crença nas tradições, a segunda se apoia na autoridade de um líder e na terceira a autoridade é assegurada pela regra reconhecida 
como competente. Uma forma de legitimação, para Weber, que importa aqui destacar, é a racionalização racional ou legal, que se refere a um sistema de normas racionais instituídas, sem a influência de motivos pessoais, de regras tradicionais pré-estabelecidas, a qual tende a diminuir a importância de outras influências (WEBER, 1998).

Diferente da situação em que existe um "líder carismático", neste caso não se 'obedece' a uma pessoa, mas a regras formalmente constituídas, que conferem a legitimidade e o direito de mando ao tipo "superior" dentro de uma escala de especialização e de competência profissional. Não se "obedece" um líder por que se acredita em normas ou tradições, mas porque se reconhece, no outro, características pessoais que motivam seguir suas ideias e, portanto, na sua capacidade de liderança. Entretanto, ao não relevar questões hierárquicas e de competências, a crença surge a partir de razões afetivas e irracionais. Tal situação, para Weber, é revolucionária, na medida em que, de forma oposta à dominação racional-legal e tradicional, não se tem regras de organização deste poder.

A forma retrospectiva implica deixar um presente em devir e partir em direção a um passado considerado "intensivamente infinito" e não um complexo de fatos ocorridos e não mais influentes na composição das motivações e percepções: o passado não parou de passar. Tais contribuições indicam caminhos que revelam além da racionalidade aparente, dos cálculos lógicos, e propiciam análises que levam em conta as irracionalidades do cotidiano. A partir de Weber $(1971 ; 1998)$, o agente, muitas vezes, se move segundo uma impulsão, ou costume, e "[...] apenas ocasionalmente é que se tem consciência do sentido (quer seja racional ou irracional) da atividade." (WEBER, 1971, p. 19). Os efeitos não desejados podem ser encontrados, para ele, no entendimento da "irracionalidade", que desempenha um importante papel nas relações sociais e econômicas.

A partir da metodologia reflexiva é possível trazer à tona questões como as possibilidades de dominação, costumes e "tradição", no intuito de explicar as diferentes ações sociais dos sujeitos. Constituir os diversos sujeitos nessa trama significa pensá-los, a partir de seus atributos, e reconstruí-los sob a luz de um tipo ideal. Mas estes sujeitos também foram "construídos", conforme várias lógicas e permanecem se constituindo, tendo em vista os cenários e arenas políticas, culturais e econômicas. Por esse motivo, o mapeamento de suas vidas e os contextos nos quais os agentes se movimentam, torna-se crucial para entender as formas de ação social, relações de poder e de dominação.

Mello (2006) ressalta que na perspectiva weberiana não é necessário supor que exista uma ordem que garanta a relação por meio de um aparato coativo ou por desaprovação so- 
cial. Em Weber, o "controle" é uma possibilidade, não uma garantia de que realmente seja exercido. Em outros termos, em uma ação racional com vistas a fins, o agente provavelmente se conduzirá "como se" reconhecesse a validade de uma norma que obriga cumprir o prometido.

Os contratos do sistema de produção, ao mesmo tempo em que garantem um mercado, estabelecem impossibilidade de negociação de cláusulas e de preços. Mesmo assim, a ideia de segurança importa mais do que o lucro. Desse modo, entendendo que as instituições não determinam o comportamento dos indivíduos e sim os orientam, não é a norma em si que explica a ação social, mas a apropriação que o ator social faz desta norma, ressaltando a importância da percepção das subjetividades. Mas, para Weber, a norma pode influenciar a conduta com diferentes graus de consciência, como o costume, o cálculo utilitário ou o respeito valorativo da norma (RAUD-MATTEDI, 2005).

As escolhas dos sujeitos encontram-se calcadas em diferentes racionalidades. Em regra, a escolha racional dos sujeitos em busca de produtividade, na contramão do discurso do bem-estar, tem justificado a permanência dos agricultores no Sistema de Produção Integrada, baseado na tradição desse cultivo.

De outro lado, as medidas de saúde pública, representando o Estado, com base nos discursos dos órgãos de saúde (INCA) e de vigilância sanitária (ANVISA), também possuem uma fala técnica e persuasiva, pautada no medo e na morte. Na medida em que desenvolvem suas estratégias discursivas e argumentos, no intuito de validarem suas falas, têm desqualificado o discurso da alteridade das organizações privadas e dos agricultores, que se mesclam, ou não, conforme o desejo dos sujeitos. As empresas de tabaco, por sua vez, além de desqualificar a fala oficial da saúde, desenvolve estratégias de "não comunicação", ou ainda, desviar a atenção das doenças causadas, reduzindo-as a um desejo de acabar com o plantio e com as empresas. Os agricultores, mesmo declarando irrelevantes as discussões sobre saúde e a importância desta para a população, demonstram estar conscientes dos problemas acarretados (RUDNICKI, 2015). Porcentagens consideráveis demonstram que as questões de saúde estão entre as principais motivações para encerrar o cultivo do fumo. Estudos demonstram que, dentre os principais motivos, estão o preço do tabaco [40,5\%], problemas de saúde e/ou por uso de agrotóxicos [32,9\%] e a falta de mão de obra [25,3\%] (VARGAS; BONATO, 2007). 
Com resultado semelhante, PERONDI et al. (2011) destacam as questões econômicas, os aspectos relacionados ao bem-estar da família e, por último, à falta de autonomia frente ao sistema de produção integrado criado pelas empresas de tabaco.

É a lógica focada em resultados; a não comunicação. No desenvolvimento da sociedade moderna, cuja as relações sociais se pautam em relações formais (mercado, dinheiro, etc.), a importância da perspectiva weberiana se concretiza em sua preocupação em compreender as ações dos sujeitos e, principalmente, os motivos dos seus interesses, de suas intenções. Apresenta-se, então, uma outra possibilidade de racionalidade, um lugar em que as interações não são mais pautadas pela mágica, pela expectativa de produção de categorias sociais a partir do trabalho; mas pelo ato de submeter-se ao sistema, por crer ser tal ocorrência inevitável. Eis o desencantamento do mundo.

\section{Considerações finais}

Se os tempos pré-modernos se caracterizavam por estarem embalados por um manto sagrado, imersos em tradições e dogmas religiosos que modulavam de forma significativa as condutas, com o desenvolvimento do cientificismo e o exacerbamento da lógica capitalista, a magia foi substituída, conforme Parsons (2010), por uma "gaiola de ferro" que provocaria um "desencantamento do mundo". Weber (1998) destaca a sujeição das subjetividades frente a comportamentos racionais.

Partimos da ideia de um confronto entre a racionalidade formal/legal (fundamentada em regras impostas), tradicional (o que sempre existiu) e substantiva (relativa a valores). Dentre as constatações observadas durante o trabalho de campo, percebemos que há uma espécie de "aversão" à mudança institucionalizada, o fenômeno denominado pelos funcionários das organizações como "zona de conforto".

Encontramos uma obediência, no sentido de um cálculo utilitário e de respeito valorativo da norma. É o desencantamento do mundo, não a partir das técnicas que fazem parte do cotidiano, mas segundo as mudanças institucionais que desencadeiam este desencantamento. Há uma imobilidade generalizada, tanto no que tange à participação em sindicatos e cooperativas, quanto na vida comunitária (quermesses, por exemplo).

As organizações públicas de saúde são percebidas pelos sujeitos como um grupo militante que luta contra o tabaco. São leis, sanções e punições impostas que contrariam as regras do jogo pautadas na tradição/valores e desqualificam as formas de uso da terra (uso de 
agrotóxicos e a ideia de monocultura). A forma de organização familiar, tendo em vista a visibilidade do trabalho infantil nestas áreas, também é contradita.

0 mato, antes naturalmente desbravado, hoje é sacralizado através da legislação decretada pelo Ministério do Meio Ambiente, fiscalizada pelo Ibama e apoiada pelas organizações e instituições do campo tabagista. 0 produtor declara sentir-se "o único errado", fadado a "obedecer". Concretiza-se a ideia de que há uma luta inconciliável, da qual não tomamos consciência e que para conduzir nossa vida de forma consciente somos forçados a ratificar certos valores e a negar outros.

As organizações privadas, por sua vez, representadas na figura do orientador técnico agrícola, ao contrário, são seguidas (obedecidas) porque se "importam" com seus modos de vida, salientando-se diferentes níveis de consciência.

Se a racionalidade institucionalizada não implica progresso, mas uma tentativa de controle, ao retornarmos ao caso da resistência "institucionalizada" às mudanças, compreendemos que as políticas públicas, advindas da assinatura da CQCT - relativas ao meio ambiente e saúde humana - têm sido enfrentadas pelos entrevistados como novas regras e sanções, não como possibilidade de ampliação de horizonte. A racionalização - e as diferentes racionalidades- tenta fornecer sentido à "não racionalidade", contida nas fragmentações e na especialização (palavras-chave nos processos de racionalização) que se apresentam no cotidiano.

A dimensão formal (legal/burocrática), ao relacionar-se com a substantiva (conformista, orientada em valores sociais), a prática (individualismo das ações cotidianas) e a teórica (construção de conceitos abstratos para explicar o mundo), esvazia parte da vida social de sentido, que nunca é apenas uma.

A reprodução social e econômica da família rural é confrontada com as categorias instituídas, como a separação entre vida doméstica e do trabalho, a contabilidade racional; a venda do trabalho, tendo em vista a multifuncionalidade (trabalho fora da propriedade) e a inserção de novas atividades, como o turismo rural, propiciam pensar em uma organização racional do trabalho livre.

Em confronto com as normas e leis, as famílias entrevistadas, perante as ideias levadas pelos órgãos públicos, se percebem como "agressoras da natureza", "produtoras de veneno" e "exploradoras de mão-de-obra infantil". Esses sujeitos vivem segundo valores pessoais, diante de um mundo moderno. Até onde as organizações irão impor seus valores para 
o mundo e deixá-los ser "jogados à fogueira"? Os agricultores continuarão a se movimentar sem se reconciliar às questões de ordem moral impostas?

Sob a perspectiva weberiana, de ordem "trágica", os homens, ao manterem seu lugar, apresentam uma perspectiva de não reflexibilidade; por isso, estão longe de construir considerações mentais sobre o seu lugar na sociedade, no ritmo da vida moderna, na "gaiola de ferro" - dilema que sinaliza esse mundo. Entretanto, quando entendemos que a principal motivação para mudar de atitude, conforme os entrevistados, é a possibilidade de danos para o núcleo familiar, destacamos a intenção de continuidade de mundo, um sentido produzido.

A família é espaço de referência e de convergência, em que o sagrado encontra abrigo. Arena em que as pancadas do martelo, ouvidas pelo credor, mesmo sendo importantes, podem não mais ser consideradas a principal motivação para a permanência no lugar comum.

\section{Referências}

ASSOCIAÇÃO dos Fumicultores do Brasil - AFUBRA. Fumicultura mundial. Disponível em: $<$ http//www.afubra.com.br>. Acesso em: 12 jul. 2015.

BALDISSERA, Rudimar. Imagem-conceito: anterior à comunicação, um lugar de significação. 219f. Porto Alegre. 2004. Tese (Doutorado em Comunicação Social) - Faculdade de Comunicação Social, Pontifícia Universidade Católica do Rio Grande do Sul, 2004.

BALDISSERA, Rudimar. Estratégia, comunicação e relações públicas. In: CONGRESSO INTERCOM, 24, 2001, Campo Grande. Anais... Campo Grande, 2001. Disponível em: <http://galaxy.intercom.org.br:8180/dspace/bitstream/1904/4539/1/NP5BALDISSERA.p df>. Acesso em: 5 ago. 2015.

BELTRÃO, Luiz. Folkcomunicação: um estudo dos agentes e dos meios populares de informação de fatos e expressão de ideias. Porto Alegre: EDIPUCRS, 2001.

BORDENAVE, Juan E. Dias. O que é comunicação rural. São Paulo: Brasiliense, 1985.

CAPORAL, Francisco Roberto; COSTABEBER, José Antônio. Por uma nova extensão rural: fugindo da obsolescência. In: CAPORAL, Francisco Roberto; COSTABEBER, José Antônio. Agroecologia e extensão rural: contribuições para desenvolvimento sustentável. Brasília: DATER, 2007. p. 5-15

EISEN, Arnold. The meanings and confusions of Weberian rationality. Journal of Sociology, British, v. 29, n. 1, p. 57-70, 1978.

FONSECA JUNIOR, Wilson Corrêa. Comunicação rural: em busca de novos paradigmas. In: DUARTE, Jorge; BARROS, Antônio Teixeira (Org.). Comunicação para ciência, ciência para a comunicação. Brasília: Embrapa, 2003. p. 95-111 
GAMSON, Willian. Falando de política. Belo Horizonte: Autêntica, 2011.

GEHRKE, Marília. Com restrições ao consumo, lei preocupa setor. A Gazeta do Sul, Santa Cruz do Sul, 3 jun. 2014. Geral, p. 9.

INSTITUTO CRESCER LEGAL.Programa Crescer Legal. Disponível em: <http://www.crescerlegal.com.br/> Acesso em: 17 nov. 2015.

KAGEIAMA, Angela A. Desenvolvimento rural: conceitos e aplicação ao caso brasileiro. Porto Alegre: UFRGS, 2008.

LEAL, Edilene. Maria de Carvalho. Racionalização e liberdade em Max Weber: possibilidades de emancipação do indivíduo contemporâneo. Aracaju: UFS, 2008.

LEVINE, Donald. Rationality and freedom: Weber and beyond. Sociological Inquiry, Seattle, v. 51, n. 1 , p. 5-25,1981.

MELLO, Maria Tereza Leopardi. Direito e Economia em Weber. Revista Direito GV, São Paulo, v. 2, n. 2, p. 45-66, jul./dez, 2006.

MENDES, Letícia. Municípios se unem na defesa do tabaco. A Gazeta do Sul, Santa Cruz do Sul, 30 nov. 2013. Capa, p.1.

PARSONS, Talcott. A Estrutura da Ação Social: um estudo de Teoria Social com especial referência a um grupo de autores europeus recentes. Weber. Petrópolis: Vozes, 2010.

PERONDI, Miguel Ângelo et al. Prospecção de meios de vida alternativos ao cultivo do tabaco no sudoeste do Paraná. Cadernos de Ciência \& Tecnologia, Brasília, v. 28, n. 3, p. 675-696, 2011.

PLOEG, Jan Dowe Van der. 0 modo de produção camponês revisitado. In: SCHNEIDER, Sergio (Org.). A diversidade da agricultura familiar. Porto Alegre: UFRGS, 2009. p. 15-56

RAUD-MATTEDI, Cécile. Análise crítica da sociologia de Mark Granovetter: os limites de uma leitura do mercado em termos de redes e imbricação. Revista de Sociologia Política, Florianópolis, n. 6, p. 59-82, abr./jun. 2005.

RUDNICKI, Carlise. "Lá e aqui”: percepções sobre os discursos antitabagistas no Vale do Rio Pardo/RS. In: ASSOCIAÇÃO NACIONAL DOS PROGRAMAS DE PÓS-GRADUAÇÃO EM COMUNICAÇÃO, Brasília, 2015. Anais eletrônicos... Brasília: Universidade Católica de Brasília, 2015. Disponível em: <http://encontro2015.compos.org.br/>. Acesso em: 10 set. 2015.

SCHLUCHTER, Wolfgang. The paradox of rationalization: on the relation of ethics and world. In: ROTH, Guenter; SCHLUCHTER, Wolfgang (Orgs.). Max Weber's vision of history: ethics \& methods. Berkeley: University of California,1979. p. 11-64 
SCHNEIDER, Sergio (Org.). A diversidade da agricultura familiar. Porto Alegre: UFRGS, 2009.

SCHNEIDER, Romeu. Tabaco, perseguição implacável. A Gazeta do Sul, Santa Cruz do Sul, 24 fev. 2011. Opinião, p. 6.

SELL, Carlos Eduardo. Racionalidade e racionalização em Max Weber. RBCS, São Paulo, v. 27, n. 79, p.153-233, 2012.

SOUZA CRUZ. Programa Amigos da Mata Nativa. 2015. Disponível em:

<https://ww.produtorsouzacruz.com.br/noticias/programa-amigos-da-mata-nativa> Acesso em: 17 nov. 2015.

SOUZA, Renato Santos de. A condição organizacional: o sentido das organizações no desenvolvimento rural. Santa Maria: UFSM, 2012.

THIRY-CHERQUE, Hermano Roberto. Max Weber: o processo de racionalização e o desencantamento do trabalho nas organizações contemporâneas. Revista da Administração Pública, Rio de Janeiro, v. 43, n. 4, p. 897-918, jul./ago. 2009.

TREICHEL, Michelle. Setor fumageiro entrega pedido a ministra. A Gazeta do Sul, Santa Cruz do Sul, 5 set. 2015. Geral, p. 20.

TREICHEL, Michelle. Setor teme pelo futuro do sistema de produção. A Gazeta do Sul, Santa Cruz do Sul, 12 nov. 2012. Rural, p. 9.

VARGAS, Marcos Antônio; BONATO, Amadeu. Cultivo do tabaco, agricultura familiar e estratégias de diversificação no Brasil. Brasília: MDA, 2007.

VIGILÂNCIA DE FATORES DE RISCO E PROTEÇÃO PARA DOENÇAS CRÔNICAS POR INQUÉRITO TELEFÔNICO. VIGITEL Brasil 2014. Brasília, 2015. Disponível em: <http://bvsms.saude.gov.br/bvs/publicacoes/vigitel_brasil_2014.pdf>. Acesso em: 20 set. 2015.

WANDERLEY, Maria Nazaré. Raízes históricas do campesinato brasileiro. In: TEDESCO, João Carlos. (Org.) Agricultura familiar: realidade e perspectivas. Passo Fundo: UPF, 2001. p. 21-55

WEBER, Max. A ética protestante e o espírito do capitalismo. 2004.

WEBER, Max. Economia y sociedade: esbozo de sociologia compreensiva. Ciudade de Mexico: Fondo de Cultura Económica, 1998.

WEBER, Max. Ensaios de Sociologia. 2. ed. Rio de Janeiro: Zahar, 1971.

WHIMSTER, Sam. Weber. Porto Alegre: Artmed, 2009.

WOORTMANN, Ellen; WOORTMANN, Klaus. 0 trabalho da terra: a lógica e a simbólica da lavoura camponesa. Brasília: UNB, 1997. 


\title{
That disenchantment of the world? \\ Communication, organization and rationalization processes in rural areas
}

\begin{abstract}
In this paper we propose to describe the disenchantment of tobacco growers from the Vale do Rio Pardo, Brazil. For this we analyze the relationship between organizations and individuals from the perspective of Weberian thought, based mainly on the concepts of rationalization and domination. We understand that the act of "obey" confronting different rationalities does not happen primarily due to the order that people believe to be legitimate, but they believe it is inevitable. Analyses were performed according to comprehensive sociology of Max Weber (1998) in a qualitative way using an analysis of discussions among small groups (Gamson, 2011) and in-depth interviews with farmers. We found out that the tobacco growers establish a resistant behavior towards the institutional changes.
\end{abstract}

\section{Keywords}

Communication. Rationalization. Domination. Organizations. Rural.

Recebido em 14/09/2015

Aceito em 01/12/2015 